Article

\title{
Impact of Optimized Packaging on Food Waste Prevention Potential among Consumers
}

\author{
Gudrun Obersteiner*(D), Marta Cociancig, Sandra Luck and Johannes Mayerhofer
}

check for updates

Citation: Obersteiner, G.; Cociancig, M.; Luck, S.; Mayerhofer, J. Impact of Optimized Packaging on Food Waste Prevention Potential among Consumers. Sustainability 2021, 13, 4209. https://doi.org/10.3390/ su13084209

Academic Editor: Gyula Kasza

Received: 28 February 2021

Accepted: 1 April 2021

Published: 9 April 2021

Publisher's Note: MDPI stays neutra with regard to jurisdictional claims in published maps and institutional affiliations.

Copyright: (c) 2021 by the authors. Licensee MDPI, Basel, Switzerland. This article is an open access article distributed under the terms and conditions of the Creative Commons Attribution (CC BY) license (https:// creativecommons.org/licenses/by/ $4.0 /)$.
Institute of Waste Management, University of Natural Resources and Life Sciences, 1190 Vienna, Austria; marta.cociancig@boku.ac.at (M.C.); sandra.luck@boku.ac.at (S.L.); johannes.mayerhofer@boku.ac.at (J.M.)

* Correspondence: gudrun.obersteiner@boku.ac.at; Tel.: +43-1-476-54-81-319

\begin{abstract}
Food and plastic waste are cited as major environmental challenges. The function of packaging is often overlooked when considering waste; however, food packaging is indispensable for hygienic protection during transport and distribution within the supply chain. An important way to prevent the premature spoilage of a variety of different food product groups is to use specially optimized packaging systems. These are able to provide a high level of protection and actively extend shelf life. However, even if novel packaging systems theoretically have great potential for waste reduction, it remains uncertain whether they will also be accepted at the consumer level and actually contribute to waste reduction within households. Three different methods were used to clarify consumers' perceptions of optimized packaging and thus the potential impact on waste generation. General perceptions have been identified by means of quantitative research among 1117 consumers. Precise information on waste generation behavior was obtained by means of food diaries. Consumer simulations were used to analyze the extent to which optimized packaging can actually have a positive effect on food waste generation at the household level. It was found that the functionality of the packaging usually ceases with the consumer. Consumers are only marginally aware of the advantages of food product packaging in the household, and do not perceive the direct connection between packaging, freshness, shelf life, and spoilage as food waste. In general, consumers rarely or never use optimized packaging at home correctly. It could be concluded that consumers' perceptions of optimized packaging in terms of potential food waste prevention are not pronounced. In summary, it can be stated that in contrast to its use in retail and transport, an optimization of packaging to avoid food waste for later use by the consumer only shows an effect in exceptional cases, or can only be achieved through targeted information campaigns. If this should be a focus topic in the future, either on the political or managerial level, this has to be taken into account.
\end{abstract}

Keywords: food waste; packaging; packaging functions; case study

\section{Introduction}

Food and plastic waste are identified by environmental and consumer organizations as major economic, environmental, and social challenges. It has been shown that food contributes between $20 \%$ and $30 \%$ of the total environmental impact of private consumption [1]. The environmental impact of food production and consumption is even worse when food is wasted rather than consumed. In their oft-cited study, FAO assume that one third of all food produced worldwide is lost due to loss or spoilage [2]. Current estimates for the European Union (EU) show that 88 million tons (MT) of food waste (including preparation residues and other non-avoidable food waste) arise along the supply chain, which is equivalent to $173 \mathrm{~kg}$ per capita and year [3]. The largest share of this waste, around $47 \mathrm{MT}$, is produced at the consumer level. Consumers, together with the retail and catering sectors, are responsible for around $70 \%$ of food waste within the EU, while the remaining $30 \%$ is attributable to production and distribution. According to a study by [4], total food waste in the EU contributes $186 \mathrm{MT}$ of $\mathrm{CO}_{2}$ equivalents to the greenhouse effect. This corresponds to $16 \%$ of the total greenhouse impact of the food value chain. 
Next to the food waste topic, the ecological impact of plastic packaging waste as a global problem has become a focus of discussion in both the public and scientific spheres in recent years. With a rising demand for plastic products, mainly due to increased living standards and the replacement of conventional materials with plastic, plastic production has undergone significant growth. Nowadays, plastics have become an indispensable part of daily life. Annual global plastic resin production has soared from only $1.7 \mathrm{MT}$ in the 1950s to approximately 348 MT in 2017, with European demand thereof being about 51.2 MT [5].

Plastics dominate almost all aspects of modern life, including the construction, transport, electrical, electronic, and healthcare sectors. However, by far the largest sector, contributing almost $40 \%$, is (single-use) packaging, which facilitates the transport of a wide range of food, drinks, and other goods [5].

Food packaging has been developed to contain food products, maintain food quality, and inform consumers about the properties of the enclosed product [6]. According to a study by [7], these primary functions are often stated as:

- Protection-to prevent the product from leaking or breaking, and to protect it from possible contaminants;

- Communication-to communicate important information about the contained food product and its nutritional content and to provide cooking instructions;

- Convenience-to provide convenience, for instance allowing consumers to reheat the contained food in a microwave;

- Containment-to provide containment for ease of transportation and handling.

In sum, the goal of food packaging is to contain food in a cost-effective way that satisfies industry requirements and consumer desires, maintains food safety, and minimizes the environmental impact. Packaging should also be designed to improve the efficiency of the product on a logistic and productive level. Efficiency in packaging design could be considered in terms of the impact on processes such as supplying, packaging, handling, storing, and transporting [8].

Thus, packaging eliminates waste along the supply chain. An important part of preventing the premature spoilage of a variety of different food product groups is the usage of specially optimized packaging systems that provide a high level of protection and actively extend shelf life. Increased usage of innovative, active, and intelligent packaging systems for food should therefore be welcomed, despite the commonly held critical views on the excessive use of plastic in all areas of life. Optimized packaging could also contribute to efforts addressing the sustainable development goal SDG 12.3, as food waste could be reduced through the improvement of packaging functions. Whether optimized packaging material will result in a decrease in environmental impacts by reducing food waste remains to be clarified.

Contrary to recent packaging research where the protective function of packaging was highlighted as its most important contribution to environmental sustainability, consumers almost exclusively refer to the packaging material when it comes to their perceptions of the environmental impact of packaging [9]. Paper-based packaging is strongly understood by the surveyed consumers to be environmentally advantageous, whereas plastic and metal are not [9].

There is an especially wide variety of drivers for retailers to optimize food packaging. An Austrian study found that by optimizing packaging, waste generation at the retail level could be reduced from $12 \%$ to $3 \%$ for meat, from $11 \%$ to $0.8 \%$ for yeast plate, and from $9.4 \%$ to $4.6 \%$ for cucumbers [10]. It was also demonstrated that optimized packaging almost always generates environmental advantages, because the environmental benefit of avoiding food waste through packaging is significantly higher than the environmental costs of packaging production and packaging optimization. In a Danish study, it could be shown that consumers assess the environmental sustainability of packaging primarily based on the material type and on what they can personally do at the disposal stage. The consumers covered in this study do not, in general, consider the impacts of production or of transport. 
Amongst the investigated packaging types, bio-based types and glass are perceived as the most environmentally sustainable ones, and plastic in general is perceived as least favorable. Laminated cartons receive a mixed perception. LCA results show that plastic and especially laminated cartons can be environmentally preferable solutions [11], even though they may be difficult to recycle.

Nevertheless, the necessity of food packaging is still hotly debated, and it comes under fire as progressive environmental pollution, despite the usefulness of its functions. Consumers, the media, and political decision-makers tend only to see packaging or certain packaging materials as problematic (especially with regard to waste generation). The primary requirement for consumers is ecological packaging; that is, they want packaging that uses less waste, incorporates recycled materials, and can be recycled when empty [12]. This gives rise to demands and strategies to avoid packaging or certain packaging materials, without the meaningfulness of such demands being verified by objective life cycle assessment data-including changes with regard to food waste volumes.

However, even though novel packaging systems show great potential for waste reduction in the retail sector [10], it remains uncertain whether they will also be accepted at the consumer level and actually contribute to waste reduction within households. The main goal of this study is therefore to determine whether packaging systems which theoretically extend the shelf life of certain foods, or help in other ways to reduce food waste, also lead to a reduction in waste at the consumer level.

In addition to a wide range of conventional packaging, a large variety of innovative food packaging is also available for the modern consumer. Individual packaging solutions include active and intelligent packaging, novel barrier materials, vacuum packaging, and modified atmospheric packaging. It has also been shown for bioplastics that the shelf life of products can be extended through their use [13]. Portioning, breathable polymer films, easy-to-empty packaging, and re-sealing options create a multitude of variants with the most diverse possibilities. Within the presented study, besides general consumer perception of food-waste-reducing packaging, the impact on food waste prevention at the consumer level has been tested, with a focus on modified atmospheric packaging, re-sealing, and portioning options.

In line with the main focus of this study, to determine whether extended shelf life due to packaging optimization leads to consumer waste reduction, the following research questions should have been answered:

- Does the consumer perceive the optimized packaging (positively or negatively)? (RQ1)

- Does the optimized packaging influence the purchase decision? (RQ2)

- Does the consumer use the optimized packaging correctly? Is the food stored in such a way as to maximize shelf life? (RQ3)

- Is the product actually longer lasting under household conditions? (RQ4)

- Is a de facto longer use of the product in optimized packaging (compared to conventional packaging) actually to be expected? How long does the specific product usually remain in the household? (RQ5)

\section{Materials and Methods}

There are a choice of reactive and non-reactive measurement methods for surveying the waste-relevant behavior of consumers [14]. In reactive measurement procedures, the persons concerned know that they are participants in a survey; this means that the measurement procedure has an influence on the variable to be measured. Reactive procedures include surveys (interviews), whereas non-reactive procedures include observation, "registering material traces" (e.g., sorting analyses), or evaluations of secondary statistical data.

Experts consider it difficult to measure the effects of waste prevention measures in general $[15,16]$. Central problems that arise here are, firstly, that avoidance measures cannot be seen and participation in them is not visually observable, in contrast to recycling measures; secondly, it is difficult to attribute a reduction in the amount of waste to prevention rather than recycling or external circumstances, such as economic situation. 
Common methods of collecting data on the effects of waste prevention include analyses of waste generation; comparative analyses using control groups; analyses using specific, usually spatially delimited campaigns; and analyses of behavioral changes using surveys and participant observation. All these methods have strengths as well as weaknesses. Frequently, the methods are too time-consuming, personnel-intensive, and cost-intensive to allow a sufficiently in-depth study generating representative results.

Surveys on food waste in general and its prevention in particular include, in addition to the above-mentioned methods, (labor-intensive) sorting analyses that enable the exclusion of the effects of other types of waste, and the keeping of so-called food diaries, in which all food that is thrown away by selected households is recorded meticulously according to type and mass. One of the main difficulties here lies in obtaining reliable participants for such studies, and also in the fact that the "self-experiment" automatically leads to changes in behavior.

In order to counteract the problems described in the analyses at the consumer level as well as possible, several methodological approaches are used or the general method of triangulation chosen. Since there is no direct measurability of the effects of the new types of packaging on food waste generation among consumers, this research strategy is also intended to aid empirical social research. Different methods or perspectives are applied to the same phenomenon in order to use the strengths of one approach to compensate for the weaknesses of the other, to achieve a higher validity of the research results, and to reduce systematic errors.

Accordingly, the surveys were planned on three levels. To answer the research questions RQ1 to RQ3, the analysis of online surveys were used to collect data concerning purchasing, storage habits, and general food handling at home, including the usual storage locations for the food products under investigation. One of the aspects addressed by the surveys was the handling of products within opened packaging. Additionally, surveys have been conducted directly at the point of sale, where customers are asked to reflect on their knowledge of different forms of packaging and their respective shelf lives while in the act of purchasing. To answer research question RQ4, results from the surveys have been supported by storage tests, in which different storage options and durations for selected food products in various packaging types have been used to simulate the behavior of consumers at home. As a third method, so-called food diaries will be used to record the amount of food waste produced by consumers, as well as the normal storage duration for selected products (RQ5).

The investigations focused on products that are sold in identical form, but in different packaging. In-depth research of Austrian supermarkets in cooperation with industry partners led to the following selection of specific products (focus areas in brackets):

- Strawberries (different packaging options)

- Tomatoes (different packaging options)

- Lettuce (general short shelf life)

- Cucumber (different packaging)

- Mushrooms (general short shelf life)

- Ham and sausages (resealable and modified atmosphere packaging (MAP))

- Cream cheese (smaller packaging unit/split packaging)

- Camembert (smaller packaging unit/split packaging)

- Marmalade (packaging size)

- Meat (ribeye) (different packaging options, focus vacuum)

\subsection{Online Survey}

During the first stage of the investigation, the waste avoidance potential of food at the consumer level and the perception and use of optimized packaging had to be surveyed, as heterogeneous strata and user types as possible. In addition to purchasing habits, reasons for decision-making, and preferences, handling of packaging in the household as well as storage habits had to be investigated. 
Here, the general handling of food at home was of more interest than the particular product, therefore products were chosen according to the availability of different packaging types. The final selection of food products for this study consisted of the following: tomatoes, strawberries, lettuce, cucumbers, mushrooms, cheese, meat, and sausages.

The use of online surveys is well established to collect empirical data in the field of consumer behavior [11]. Although convenience samples have several limitations, it seemed appropriate for an initial assessment of consumer perception for the question at hand.

The survey was based on a structured online questionnaire, which was made available to the participants via various social media channels, including the social media and customer magazine of the biggest Austrian retailer, over a period of 16 weeks. The advantage of an online survey compared to telephone or personal interviews is the independence of the participants in terms of time and place. Interviewer effects can also be eliminated. Disadvantages include the requirement for internet coverage and technical knowhow.

A standardized questionnaire with mainly closed questions was used. It was structured in five main sections and 27 questions. The first section was about general issues related to purchasing. Among other topics, questions were asked about responsibility for purchasing and cooking. General and packaging-specific influences on the purchase decision were analyzed. The next section dealt with transport issues followed by a section dealing with details on storage. In this third part, consumers were asked about their usual places for storage of the selected products of interest. The fourth section dealt with purchase behavior. For each of the selected products, people were asked which packaging option they would prefer. The packaging options have been presented as pictures and described as text. Products that have been available in different packaging have been included in this part of the questionnaire. This included strawberries (5 varieties), cream cheese (portion packaging and cups), cherry tomatoes ( 7 varieties, including open plastic cups, cups with lids, cups with perforated foil, carton with bio-plastic, or plastic cups with pouches), ham (3 varieties), meat (5 vacuum skin, MAP, plastic tray with stretch film), and Camembert (2 varieties, including portion packaging).

In total, 1489 respondents answered the questionnaire. This resulted in 1152 fully completed questionnaires and yielded 1117 valid questionnaires after data cleaning and excluding of obviously incorrectly filled out questionnaires. The data was analyzed electronically using the static analysis software SPSS. The frequency of the participants' responses was measured, and cross-tabulations by gender, age, education, and income were performed to identify potential correlations between the variables.

This sample (Table 1) is not representative for the Austrian population, as its composition deviates from the demographic distribution. Mainly female participants were recruited for the survey (77\%); it can, however, be assumed that women are predominantly responsible for grocery shopping in the household. Considering the age structure of the sample, a strong influence of the survey method on the composition of the respondents by age becomes apparent. Partakers over 60 are clearly underrepresented, with only $7 \%$ participation. This group can be assumed to contain the highest number of people not using the Internet regularly, which explains the low participation in an online survey.

In terms of education and income, a clear influence of the chosen survey methods on the composition of the participants becomes apparent. There was a tendency for people with a higher level of education ( $47.5 \%$ state that they have a (technical) college or university degree, while another $30 \%$ have a general qualification for university entrance) to take part in the survey. The Austrian structure of education has been transferred into the international standard classification of education (ISCED). The majority of respondents said they lived in urban areas (63\%). Considering this, the following results cannot be assumed to be representative; nevertheless, tendencies can be indicated, and a good basis for further studies has been created. To identify the major influence of demographic deviation, crosstabulation of main variables has been performed using Cramer's V. A weak relationship could be proven only in a few cases (Table 2). For example, younger people are less likely to see the need for packaging per se than older people. They store, for example, tomatoes 
more often in the original packaging than elder people. Although packaging is more relevant for younger people, still only $24 \%$ of the group under 29 state that packaging influences their purchase decision. For most variables, no relationship could be identified.

Table 1. Sample structure.

\begin{tabular}{ccc}
\hline Characteristics & Share in the Sample & Result \\
\hline \multirow{3}{*}{ Gender } & female & $77 \%$ \\
& male & $20 \%$ \\
& other & $3 \%$ \\
\hline \multirow{3}{*}{ Age group } & $15-29$ & $38.0 \%$ \\
& $30-44$ & $31.8 \%$ \\
& $45-59$ & $23.5 \%$ \\
Education & $>60$ & $6.6 \%$ \\
& compulsory school (ISCED 2) & $1.8 \%$ \\
& unprenticeshiph or high school certificate (ISCED 3 to 5) & $50.7 \%$ \\
& $<\in 1300$ & $47.5 \%$ \\
\hline \multirow{2}{*}{ Income } & $€ 1301-€ 2200$ & $5.9 \%$ \\
& $€ 2201-€ 3200$ & $19.6 \%$ \\
& $€ 3200-€ 4200$ & $12.4 \%$ \\
& $>€ 4300$ & $14.6 \%$ \\
& no answer & $7.3 \%$ \\
\end{tabular}

\subsection{Survey at the Point of Sale (PoS)}

For the point-of-sale survey, a quantitative computer-assisted personal interview was chosen as the survey method. The quantitative questionnaire allows for a standardized and highly structured survey, which minimizes factors that could disturb the discourse between the respondents and the interviewers. All participants were asked the same questions in the same order, enabling a comparable interview situation for all respondents. The refusal rate tends to undergo a significant decrease in a face-to-face interview setting, as compared to answers procured through a written survey.

The quantitative research was conducted on a sample of 240 respondents in two supermarkets of the retail chains REWE and Spar in Vienna on different days of the week and at different times. The costumers were asked after shopping, in the area after the cash registers where many visitors linger anyway to put their purchases in bags.

Consumers were asked about their perception of food packaging at the point of sale, and were presented with questions regarding their purchase motives and decisions. The participants were asked about packaging in general, and about specific products chosen during the shopping trip. Products were chosen that were available at the market both in different packaging sizes, and in different packaging variants. The respondents were each asked about a product they had bought. A distinction was made between buyers of strawberries, snack tomatoes, ham, camembert, cream cheese, and meat. The focal points of the survey were, firstly, consumer perception of food packaging; and secondly, to determine the motives for purchasing food products contained within a certain form of packaging, and the domestic storage and handling of the product. The interview was directly recorded by the interviewer using a tablet (computer-assisted personal interview). 
Table 2. Main variables cross-tabulated using Cramer's V.

\begin{tabular}{|c|c|c|c|c|c|c|c|c|}
\hline & \multicolumn{2}{|c|}{ Age } & \multicolumn{2}{|c|}{ Gender } & \multicolumn{2}{|c|}{ Education } & \multicolumn{2}{|c|}{ Income } \\
\hline & $\begin{array}{c}\text { Cramer's } \\
\mathrm{V}\end{array}$ & $\begin{array}{c}\text { Approx. } \\
\text { Sig. }\end{array}$ & $\begin{array}{c}\text { Cramer's } \\
\mathrm{V}\end{array}$ & $\begin{array}{c}\text { Approx. } \\
\text { Sig. }\end{array}$ & $\begin{array}{c}\text { Cramer's } \\
\mathrm{V}\end{array}$ & $\begin{array}{l}\text { Approx. } \\
\text { Sig. }\end{array}$ & $\begin{array}{c}\text { Cramer's } \\
\mathrm{V}\end{array}$ & $\begin{array}{c}\text { Approx. } \\
\text { Sig. }\end{array}$ \\
\hline \multicolumn{9}{|c|}{ Reasons for Choosing Food (RQ1) } \\
\hline Price & 0.142 & 0.000 & 0.027 & 0.664 & 0.075 & 0.275 & 0.155 & 0.000 \\
\hline Origin/regionality & 0.084 & 0.050 & 0.106 & 0.002 & 0.106 & 0.027 & 0.064 & 0.462 \\
\hline Organic & 0.083 & 0.051 & 0.109 & 0.001 & 0.221 & 0.000 & 0.070 & 0.360 \\
\hline $\begin{array}{l}\text { Freshness/shelf } \\
\text { life }\end{array}$ & 0.149 & 0.000 & 0.016 & 0.869 & 0.169 & 0.000 & 0.095 & 0.073 \\
\hline Quality/taste & 0.007 & 0.996 & 0.134 & 0.000 & 0.051 & 0.708 & 0.111 & 0.017 \\
\hline Portion size & 0.074 & 0.107 & 0.030 & 0.615 & 0.039 & 0.884 & 0.096 & 0.068 \\
\hline Food packaging & 0.115 & 0.002 & 0.076 & 0.041 & 0.050 & 0.739 & 0.088 & 0.124 \\
\hline Brand & 0.103 & 0.008 & 0.101 & 0.000 & 0.070 & 0.366 & 0.060 & 0.539 \\
\hline $\begin{array}{l}\text { Comprehensible } \\
\text { info }\end{array}$ & 0.053 & 0.379 & 0.050 & 0.249 & 0.075 & 0.272 & 0.087 & 0.132 \\
\hline Label (fair trade) & 0.053 & 0.379 & 0.069 & 0.069 & 0.041 & 0.864 & 0.052 & 0.690 \\
\hline Ingredients & 0.051 & 0.409 & 0.082 & 0.024 & 0.048 & 0.771 & 0.049 & 0.752 \\
\hline \multicolumn{9}{|c|}{ Influence of Packaging on Purchase Decision (RQ2) } \\
\hline Type of material & 0.186 & 0.000 & 0.125 & 0.000 & 0.127 & 0.003 & 0.077 & 0.247 \\
\hline $\begin{array}{l}\text { View on the } \\
\text { product }\end{array}$ & 0.068 & 0.159 & 0.067 & 0.080 & 0.069 & 0.380 & 0.046 & 0.792 \\
\hline Product protection & 0.103 & 0.008 & 0.105 & 0.002 & 0.076 & 0.260 & 0.037 & 0.909 \\
\hline Size & 0.076 & 0.092 & 0.039 & 0.420 & 0.104 & 0.035 & 0.083 & 0.177 \\
\hline Design & 0.149 & 0.000 & 0.068 & 0.076 & 0.121 & 0.006 & 0.075 & 0.281 \\
\hline $\begin{array}{l}\text { Consumer } \\
\text { friendliness }\end{array}$ & 0.060 & 0.254 & 0.052 & 0.220 & 0.070 & 0.357 & 0.036 & 0.919 \\
\hline Longer shelf life & 0.069 & 0.155 & 0.155 & 0.000 & 0.075 & 0.284 & 0.081 & 0.193 \\
\hline Subdivision/portioning & g 0.016 & 0.963 & 0.023 & 0.749 & 0.063 & 0.480 & 0.031 & 0.959 \\
\hline \multicolumn{9}{|c|}{$\begin{array}{l}\text { Storage Direct after Purchasing (in Orig. Packaging, in Opened Orig. Packaging, in Other Packaging, without Packaging) } \\
\text { (RQ3) }\end{array}$} \\
\hline Tomatoes & 0.078 & 0.058 & 0.117 & 0.000 & 0.076 & 0.176 & 0.105 & 0.000 \\
\hline Strawberries & 0.094 & 0.003 & 0.090 & 0.020 & 0.083 & 0.056 & 0.071 & 0.313 \\
\hline Meat & 0.165 & 0.000 & 0.100 & 0.004 & 0.108 & 0.000 & 0.120 & 0.000 \\
\hline Sausages & 0.171 & 0.000 & 0.118 & 0.000 & 0.124 & 0.000 & 0.117 & 0.000 \\
\hline Cheese & 0.126 & 0.000 & 0.089 & 0.023 & 0.079 & 0.109 & 0.086 & 0.032 \\
\hline
\end{tabular}

\subsection{Consumption Simulation}

Based on the results of the online survey, focus groups, and surveys at point of sale, a test set-up was developed to simulate packaging solutions under different storage conditions. Selected product packaging was compared under real-life conditions (e.g., storage refrigerator/room temperature, unpacking/repacking, briefly remaining at ambient temperature, removal of foodstuffs), in order to reveal the influence of optimized packaging on waste generation.

When purchasing the products for the trial in the supermarket, attention was paid to the use-by and best-before date in order to create the fairest possible test conditions for the respective product in the different packaging and storage forms. The products were then stored in a refrigerator, where temperature measurements had been taken in advance (there was a range of 5 to $8^{\circ} \mathrm{C}$ ).

The following parameters were considered: water loss (product-specific), visual appearance (color, surface texture, firmness), olfactory impression (smell), and overall gustatory impression (taste). No additional chemical or microbiological tests were carried out. Exclusion criteria included mold, rot, strong odor or taste, color change, or any other visible harmful characteristics.

In order to exclude any faulty batches, 3-5 parallel approaches were selected per comparison product. A total of 15 panelists were recruited for the sensory tests. As the 
idea was to simulate household conditions, preference was given to amateur tasting over expert tasting.

The procedure involved an initial visual and olfactory evaluation followed by a gustatory evaluation in the form of blind tasting. The focus was on the instinctive assessment made by the subjects. The testers were asked to trust their senses and to evaluate the product instinctively (assumption: "I take the product out of the refrigerator and decide on the spot whether I would still eat it or throw it away").

The evaluation by the test persons was done by assigning points, based on the Austrian school grading system ( 1 = very good or product corresponds to my expectations; $5=$ not edible, I would throw it away). In addition, the test persons had the opportunity to record conspicuous features and more detailed descriptions in writing. Finally, the results (averaged values) of each packaging or storage variant were ranked for the respective assessment day.

\subsection{Diary Surveys}

In order to determine how consumers would deal with the selected products in their own household, so-called food diaries were handed out. The evaluations were designed to provide information on whether consumers recognize shelf-life-extending packaging and use it accordingly. Additionally, details were obtained concerning the duration over which products usually remain in the household before being eaten or spoiling.

Potential participants were asked to keep a record of at least two of the selected food products in the diary. The diaries were distributed personally to consumers in supermarkets, who were given the options of returning the diary entries by e-mail using a photo or scan, by fax, by post, or by filling in digital diaries using their own PC.

The so-called "food diary" represents a detailed record of purchased products. The aim was to record the following data:

- Specific product purchased (including the brand to infer the packaging type)

- Date of purchase

- Number of grams purchased

- Details on location of storage (at room temperature or in the refrigerator)

- Details on type of storage (in original closed packaging, in original opened packaging, or unpacked)

- Details on storage time and consumption, for which consumers were asked to record:

- Date when all or the last portion of the product was completely consumed, and/or

$0 \quad$ Date when a portion or all of the product was discarded;

- Weight in grams (g) or kilograms (kg) of the portion of the spoiled product;

$0 \quad$ Date and weight of other processing (when the product was processed or preserved in another way, such as freezing, canning, etc.);

- Reason for disposal/note (here the consumer should indicate why the product had to be disposed of).

A total of 30 completed diaries were returned, and 56 different product groups (e.g., cheese, ham, tomatoes, bread) were recorded.

\section{Results}

3.1. Online Survey Results

3.1.1. Packaging from the Consumer's Point of View: Attitudes and Perceptions

In order to evaluate attitudes towards food packaging and consumer perceptions, the study participants were asked to name the benefits of food packaging that are most important to them and to indicate their agreement with statements about packaging. The results clearly indicate that consumers recognize the advantages of packaging during transport and in retail, and perceive them as important. More than half $(60 \%)$ of the participants named "protection during transport and in store" as the most important function of food packaging. Product safety and hygiene are seen by $47 \%$ of participants 
as essential properties of packaging. The shelf life extension function of packaging is also perceived and named as an important function $(36 \%)$. Other essential aspects mentioned were information about the product $(30 \%)$, resealability $(23 \%)$, and portionability $(12 \%)$.

The participants of the study perceive the protective function of food packaging and name it as the most important function in terms of technical, hygienic, and shelf life extending product protection. However, the awareness of a link connecting food packaging with the simultaneous reduction of food waste is absent. Only $23 \%$ of the participants recognize that packaging can help prevent food waste, and only $6 \%$ saw product protection at home as an important function of packaging.

Less than $60 \%$ of the respondents recognize that storing food in its original packaging keeps it fresher for longer (Figure 1), or are aware that keeping food in the original packaging prolongs the shelf life. On the other hand, more than $90 \%$ of respondents feel that food is over-packaged nowadays.

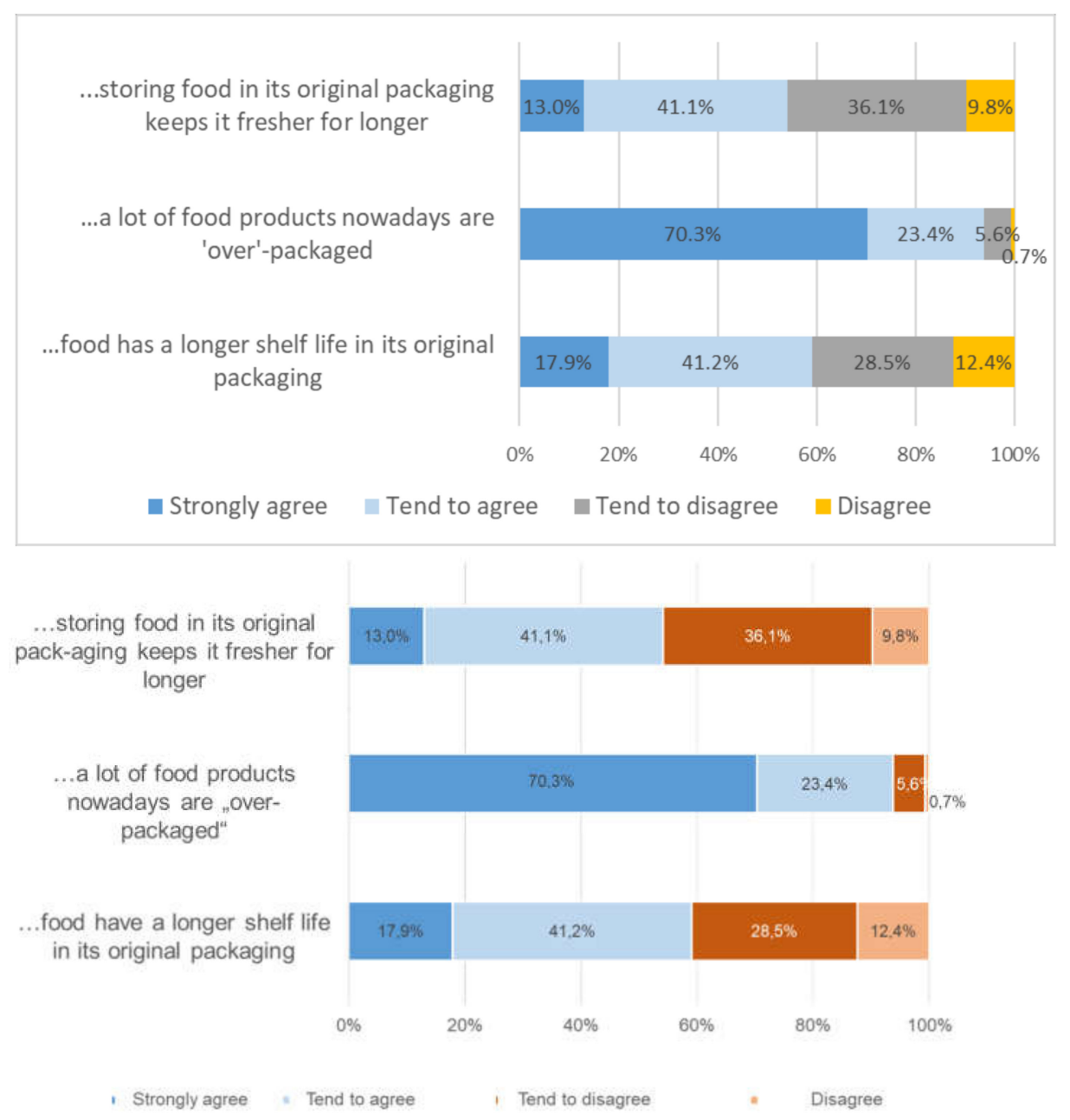

Figure 1. Perception of optimized packaging: statements about food.

The results indicate that packaging plays only a minor role in product selection. For most of the respondents, the origin and quality of food as well as the price are the main reasons for the choice of a specific food product. Only approximately $19 \%$ of those surveyed stated that packaging is a decisive factor in the choice of food (Figure 2). 


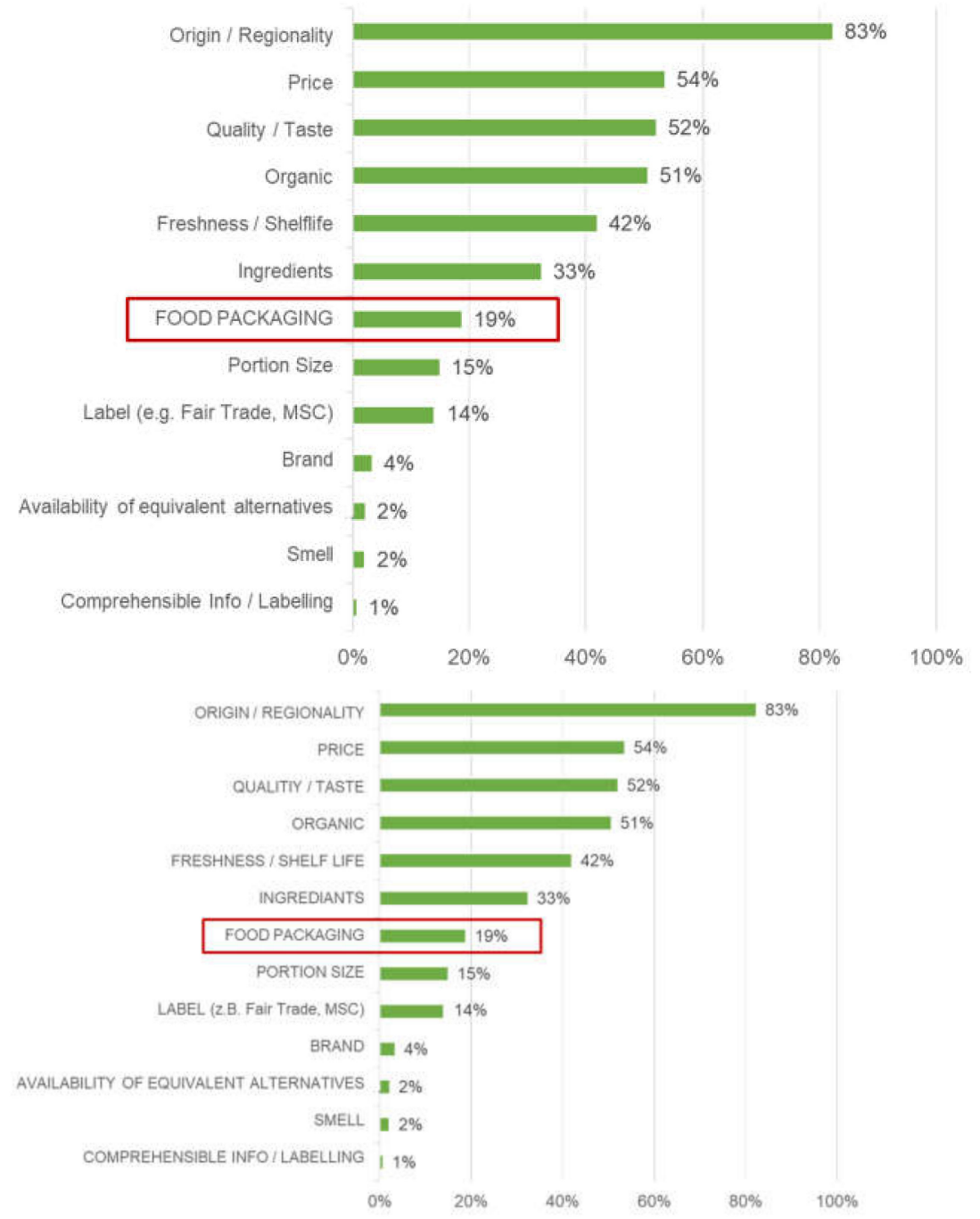

Figure 2. Perception of optimized packaging: reasons for choosing food.

On being asked for the reason for choosing a certain type of packaging, the packaging material was found to have the greatest influence on the purchase decision $(69 \%)$. Consumer friendliness, a good view of the product, and the optimum packaging size were also found to play a role in the purchase decision. Only $20 \%$ of the respondents mentioned the length of shelf life as a factor in their choice of packaging.

When asked to assess the relevance of the environmental problem caused by packaging compared to that caused by food waste, $72 \%$ of respondents perceived packaging waste as the more serious environmental problem. An analysis of gender-specific perception shows that about half of the male participants see the problem of packaging waste as more serious than food waste, compared to around two thirds of females.

\subsubsection{Handling of Packaging and Storage of Food at Home}

In order to determine the potential for food waste reduction through optimized packaging at home, the habits of the respondents were investigated with regard to product storage and handling of product packaging. It can generally be assumed that incorrectly stored products are disposed of more frequently. On the other hand, correct usage of optimized packaging can extend the shelf life of food in the household. The participants were asked about their storage habits and use of packaging for different products, so that any differences in the use of the individual product groups could be determined and the further use of optimized packaging in the household could be surveyed. 
Concerning the individual product groups, there is a clear tendency to store products in the refrigerator. Tomatoes saw the lowest/relatively low refrigerator storage at only $50 \%$, and were stored at room temperature by half of the participants. In general, food product groups were seldom stored in the freezer, with the exception of fresh meat, which was frozen by a quarter of the participants.

Considering consumer storage habits at home, there is a clear tendency to store food products outside the original packaging. This was found to be particularly true for fruit and vegetables. It was found that less than $50 \%$ of the respondents store these products in their original closed packaging (Figure 3), and for tomatoes it was less than 30\%. Cucumbers $(48 \%)$, lettuce $(36 \%)$, and tomatoes $(41 \%)$ are mainly stored without packaging, while about $60 \%$ of the respondents leave sausages, cheese, and meat in their original packaging. However, the percentage of participants who take sausages, cheese, and meat out of the packaging immediately after purchase and repack them in different packaging for further storage is larger than for any other product; the highest percentage is seen for sausages and cheese, at about a quarter.


Figure 3. Handling of unopened packaging at home (Number of replies: 1117). 
Once the packaging has been opened, products are packed in another container or stored loose. Lettuce, cucumbers and tomatoes are more often stored loose, whereas cheese and sausages tend to be packed in another container for further storage. Compared to the other products, fresh meat is more likely to be frozen after the packaging has been opened.

Incorrect storage and handling of packaging can contribute significantly to the amount of food waste generated in the household. Instructions for correct storage are sometimes found on food packaging. Within the framework of the present study, it was ascertained to what extent the consumers perceive and follow these instructions.

Interestingly, some consumers state that despite understanding these instructions, they have not changed their behavior regarding food storage. Of the participants, $88 \%$ answered that storage instructions on product packaging had no effect on their storage habits. Broken down by product, a comparison of the individual product groups shows a clear discrepancy in the perception of storage instructions on "sensitive" products such as meat, fish, cheese, or sausages, compared to fruit and vegetables. About half of the respondents stated that they had seen and followed the storage instructions on sensitive products, whereas a clear majority of consumers did not notice them for fruit and vegetables (Figure 4).
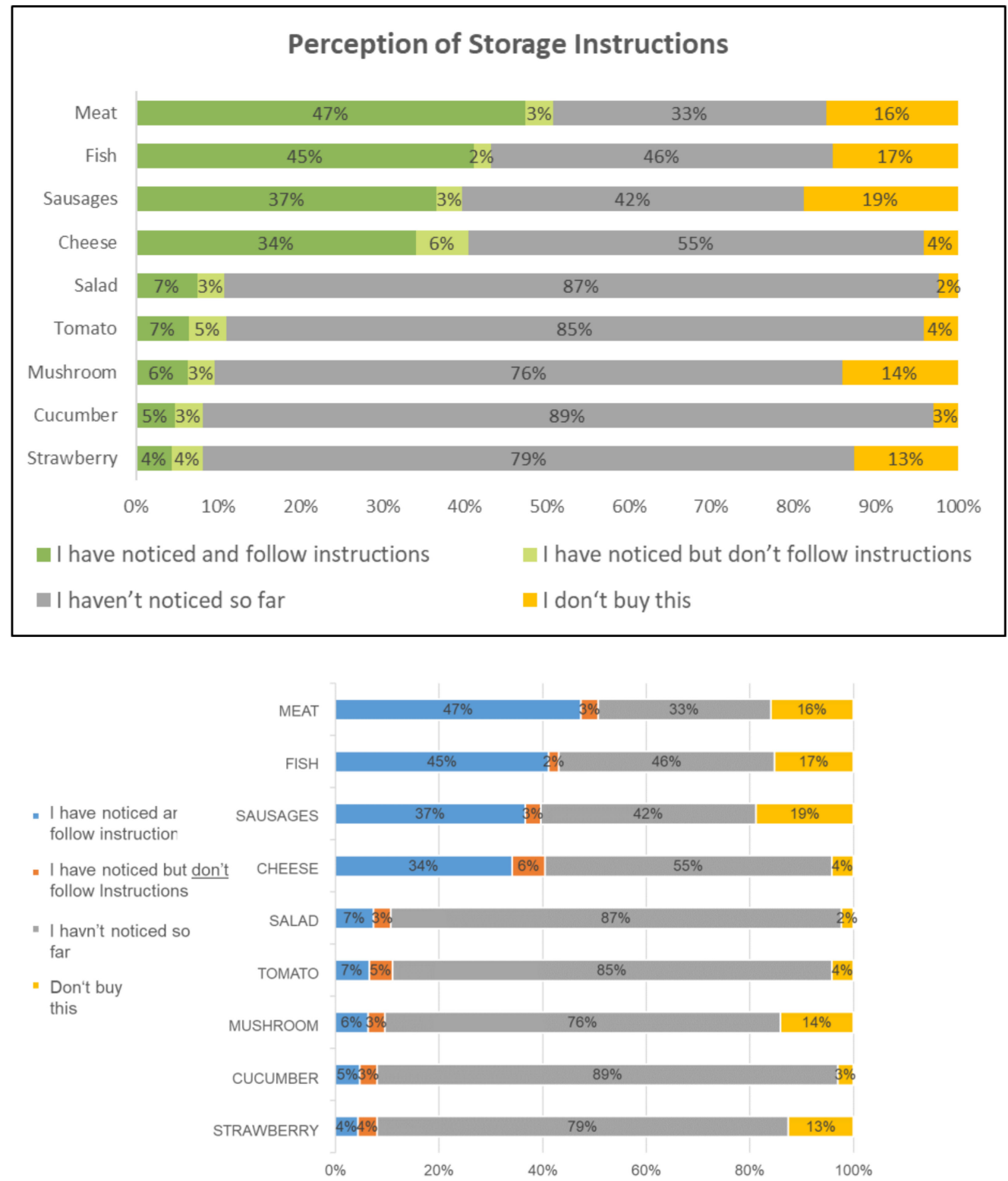

Figure 4. Perception of storage instructions ((Number of replies: 1117). 


\subsubsection{Influence on Purchase Decision}

The respondents were presented with variously assorted packaging options for the selected products, and were asked to choose the packaging variant they would be most likely to buy. They were then asked to justify their decision. For example, two packaging options were presented for cream cheese: the first, a $150 \mathrm{~g}$ plastic cup, and the alternative, a $120 \mathrm{~g}$ split pack with 8 individually packaged portions. A clear majority $(90 \%)$ of respondents would choose the plastic cup option. For both packaging variants, the appropriate portion size plays a decisive role in the choice of product (Figure 5): $85 \%$ of respondents who chose the split pack option gave their reason as portion size. These participants also tended to be of the opinion that the product stays fresh longer when packed in single portions $(63 \%$ of those who would prefer the split pack variant compared to $24 \%$ of those who would choose cream cheese in a cup).

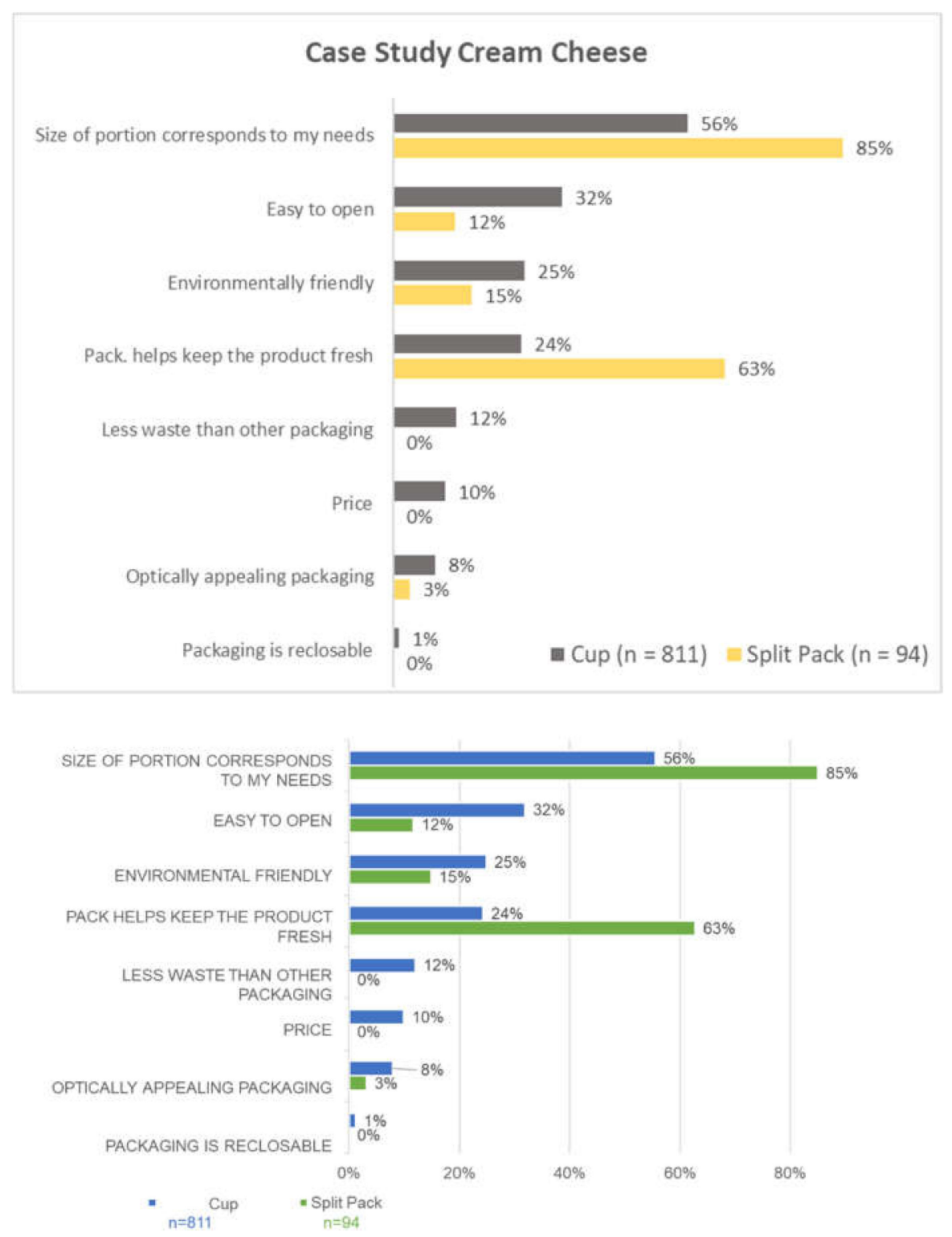

Figure 5. Survey results: reasons for cream cheese packaging variant choice ( $\mathrm{n}=$ number of replies).

When choosing ham, the majority (63\%) of respondents would opt for the unpackaged meats option at the delicatessen counter, and about a quarter $(25 \%)$ would prefer the resealable packaging option (MAP). Respondents (557 persons) stated that their choice of the delicatessen counter was mainly because of the freely selectable product quantity (91\%), 
and they also perceive the delicatessen packaging as less waste-intensive (64\%) and more environmentally friendly $(19 \%)$. Respondents opt for the resealable MAP variant because of its resealability $(67 \%)$, the extended shelf life due to the protective atmosphere (44\%), and the optimal portion size $(35 \%)$. Other decision criteria included product protection $(25 \%)$, no waiting time (in contrast to the delicatessen counter) $(21 \%)$, and extended shelf life after opening (19\%). In contrast, price (5\%) and the visual design of the packaging $(9 \%)$ had only a marginal effect on the choice of packaging. Those who would have chosen the third packaging variant (plastic top and bottom film with protective atmosphere) chose it mainly because of the extended shelf life due to the protective atmosphere $(47 \%)$. Other decision criteria are the optimal portion size $(38 \%)$, product protection $(32 \%)$, and no waiting time at the counter $(25 \%)$.

\subsection{Consumer Simulation Results}

The consumer simulation was carried out under conditions as close to real life as possible. This was intended to provide information on which types of packaging would be preferable in terms of longer shelf life under which circumstances. During the simulation, participants were asked whether they would still eat the product after various time periods. In the following descriptions of the consumer simulation, two examples of food products under investigation, ham and cheese, are given.

\subsubsection{Ham}

Ham and sausage products are available in a wide variety of packaging forms. In order to investigate the influence of the packaging on the shelf life, the selection of an identical type of ham (from the same manufacturer) as well as the availability of different packaging forms in one or the same food outlet (supply chain) are prerequisites.

After thorough research, oven-baked ham from one producer, which was available in three different forms of packaging, was chosen. The following packaging types have been taken into account:

1. Resealable MAP (modified atmosphere packaging) of $100 \mathrm{~g}$ (best before date: 17 February 2019);

2. Flexible MAP plastic top and bottom foil of $140 \mathrm{~g}$ (best before date: 6 February 2019);

3. Delicatessen (deli) paper from the delicatessen section (no best before date, quantity freely selectable, $140 \mathrm{~g}$ used for the trial).

The ham was stored in the lower compartment of the refrigerator for the entire experimental period, with an average storage temperature of about $5^{\circ} \mathrm{C}$. About $24 \mathrm{~h}$ after purchase and subsequent sample preparation, the ham was assessed or tasted for the first time. Each type of packaging had five parallel approaches.

After the visual and olfactory assessment, the top piece of ham was taken from each packaging variant and divided according to the number of tasters. For the tasting, only two of the five parallel approaches were used per packaging variant in order not to overtax the testers. Both the selection of the respective packaging and the allocation of sample numbers (from 1 to 12 ) were determined at random.

For the evaluation, each packaging variant was assigned its rank, using the cumulative number of points in ascending order (1st rank = lowest). The packaging that achieved the best score was the flexible MAP plastic top and bottom foil packaging. The advantage of the packaged product in contrast to ham from delicatessens becomes apparent from the 5 th day onwards (Figure 6). This is especially evident from the olfactory and gustatory evaluation. From the 8th day of the trial, all test persons would have thrown the ham from the delicatessen department away, whereas they would have kept the packaged variants until the 12th day (Figure 6). This results in a longer "perceived shelf life" of the packaged forms by about one third. The perceived shelf life was defined as the date when people would have disposed of the ham. Figure 6 shows the percentage of test persons who perceive the ham as edible. The experiment ended on day 13, after which all test persons would have thrown the ham away regardless of the packaging form. 


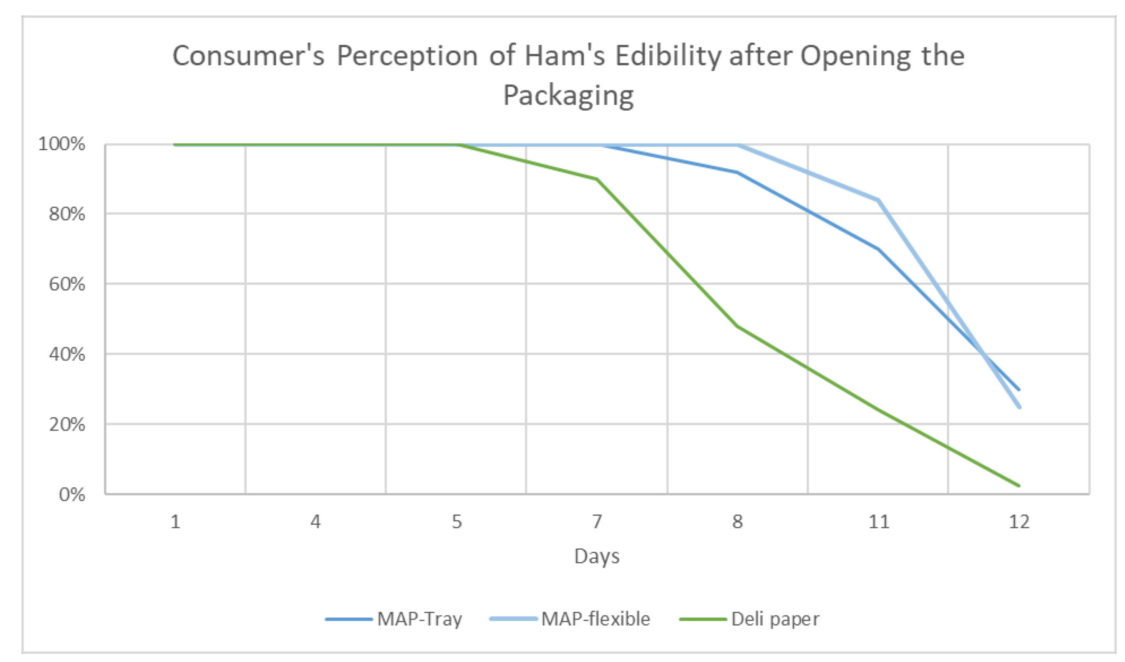

Figure 6. Perceived shelf life of oven-baked ham over test period.

\subsubsection{Fresh cheese and Camembert}

The fresh cheese "Bresso" is available in two different product packaging forms in the Austrian grocery retail market:

(a) Plastic cup with aluminum plate and removable plastic lid of $150 \mathrm{~g}$ (best before date: 12 March 2019);

(b) Eight portions in aluminum-coated foil and cardboard packaging of $120 \mathrm{~g}$ (best before date: 10 February 2019).

Within the framework of the consumer simulation, the hypothesis that the product in the plastic cup tends to spoil more quickly due to contamination during use (removal with knife) had to be tested. To simulate household conditions for the plastic cup variant, different removal scenarios were tested:

Scenario A: Use of clean knives.

Scenario B: Use of contaminated knives. The knife was previously brought into contact with the sandwich. The possible contamination with lactic acid bacteria, yeast fungi, and so on, through breadcrumbs or other substances from the butter, could affect the shelf life of the product.

Scenario C: A knife previously licked by the test person was used. Germs, enzymes, and so on in the saliva could have a shelf-life-reducing effect on the product.

Both packaging variants were purchased on the same day in the same supermarket and temporarily stored in the refrigerator $\left(8-9{ }^{\circ} \mathrm{C}\right)$ for a few days. The experiment was carried out with three parallel samples each.

When preparing for the visual and olfactory assessments, the plastic lid was removed from the cup and the aluminum cap was pushed back so that the product was visible to the test persons. After the visual and olfactory evaluation by each individual test person, and return of the samples to the refrigerator, a blind tasting of the fresh cheese took place. The experiment was terminated as soon as more than half of each parallel batch (i.e., two out of three parallel samples) was classified as no longer fit for consumption by the majority of the test persons, or was already judged to have spoiled by the experimenter after careful assessment.

In total, the trial lasted for 41 days, by which time the best-before date of the plastic cups was 7 days overdue, and that of the portioned packaging had expired more than one month before.

The results show a better performance of the portioned packaging in terms of shelf life (Figure 7). On the last day of the evaluation, the plastic cups were classified as spoiled by the test persons, whereas the portioned packaging cheese still scored good marks and was thus judged to be safe or fit for consumption by the majority of the test persons. When all 
assessment categories (appearance, smell, and taste) were taken into account, the portioned packaging was ranked as superior to the plastic cup.



Figure 7. Perceived shelf life of cream cheese over test period (SA = Scenario A: removal with clean knife; SB = Scenario B: removal with contaminated knife; SC = Scenario C: removal with licked knife).

An evaluation of the second cheese, Camembert, showed similar results as in the Bresso trial. Not only do the results indicate a longer shelf life for portioned packaging compared to the other forms of storage, but there was also a similarity in the number of test persons who rated the majority of the portioned Camembert as still edible on the final day of the evaluation. As in the Bresso trial, the test subjects still showed a willingness to eat/use the portioned Camembert on the final day of the trial, even though the best-before date had been exceeded by almost one month for all variants.

\subsection{Diary Survey Results}

A total of 30 completed diaries were returned and 56 different product groups (e.g., cheese, ham, tomatoes, bread) were recorded. Figure 8 displays, on average, the period 
that frequently purchased product groups remain in the household before being consumed. In addition, the point at which the product is disposed of, if not consumed, was recorded.

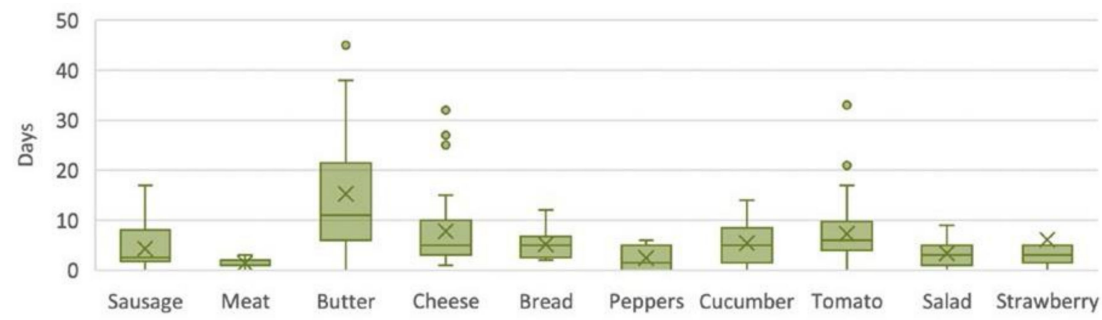

Figure 8. Duration of stay of selected food in households.

It was found that butter was not disposed of by any of the participants, but remained in the household for an average of 11 days, the longest period of all investigated products. Tomatoes are stored for an average of 6 days before consumption, although a small quantity are disposed of after an average of 4 days. Strawberries remain in the household for less than a week on average before they are consumed or disposed of. On average, strawberries and lettuce are thrown away after the shortest period, only 3 days, which is to be expected given the short shelf life of these products. Sausages and meat are very rarely disposed of and on average are consumed by the household on the same day of purchase, or after two days at the latest. Bread also remains in the household for less than a week on average; after this time, some households continue to consume it, while others dispose of it.

\section{Discussion}

Private households have a decisive influence on the generation of food waste. Accordingly, a reduction in food waste requires a change in behavior (be it choice of different packaging or improved storage). In line with the main focus of this study, to determine whether extended shelf life due to packaging optimization leads to consumer waste reduction, the following questions have to be addressed:

- How does the consumer perceive the optimized packaging (positively or negatively)?

- Does the optimized packaging influence the purchase decision?

- Does the consumer use the optimized packaging correctly? Is the food stored in such a way as to maximize shelf life?

- Is the product actually longer lasting under household conditions?

- Is a de facto longer use of the product in optimized packaging (compared to conventional packaging) actually to be expected? How long does the specific product usually remain in the household?

\subsection{Consumer's Perception of Optimized Packaging}

In general, studies that specifically address consumer perceptions of packaging are rare. Lindh et al. [17] summarized that for the most part, studies investigating consumer perceptions of packaging are either limited to a set of predefined packaging-related aspects, analyze the communicative function of packaging, or focus on the graphic design used for labeling or packaging material. In a new systematic review on consumer perceptions of packaging, it was concluded that there is very little research that examines consumers perceptions of food packaging [18]. In particular, there is insufficient research on the role of consumers' perceptions in reducing food waste.

The results of the online survey indicate that consumers do not generally perceive optimized packaging as prolonging shelf life. Consumers tend to perceive products as over-packed, and they are not aware of the fact that storing food in its original packaging prolongs its freshness and extends shelf life.

In a well-respected study by WRAP on consumer attitudes to food waste and food packaging, it was shown that consumers identify safety and hygiene, communication of information, and food protection (mainly during transport) as the top three benefits of food 
packaging [19]. Only $13 \%$ of participants in the WRAP survey recognized the role of food packaging in protecting food in the household. This finding agrees with the results of the study described here, in which $60 \%$ of survey participants see the most important function of food packaging as protection, while less than one quarter of participants recognize the potential of packaging in reducing food waste in the household. Wohner et al. [20] point out that the main challenge for all stakeholders involved in the packaging design process is that consumers remain unaware of the importance of appropriate packaging for reducing food waste.

In addition to the lack of awareness concerning packaging as a means for extending shelf life and related food waste prevention, the respondents' perception of packaging in general is striking. More than $90 \%$ of the respondents strongly agree or at least agree to the statement that food is overpacked nowadays. It has already been demonstrated by Plumb et al. [19] in their 2013 study that the two most frequent negative associations with packaging are 'uses too much material' (52\%) and 'bad for the environment' (50\%). Similar results have been presented in a study based on a consumer survey carried out in Sweden [17]. A review of recent packaging research emphasizes the protective function of packaging as its most important contribution to sustainable development, and consumers almost exclusively refer to the packaging material when it comes to their perceptions of the negative environmental impact of packaging. In response to the question of whether packaging or food waste is the bigger environmental problem, $72 \%$ of respondents in this study chose packaging as the most serious environmental issue. This result is mirrored in an Italian survey in which $60 \%$ of consumers were convinced that packaging has a greater environmental impact than food waste [21].

Summarizing the output of international studies on functional characteristics of packaging that influence purchase decision, the most important characteristics appear to consist of easy opening, resealability, packaging size, information given, and color [17]. These results have been obtained by explicitly asking consumers to assess the advantages of packaging, and so can only partly be compared to the study described here, in which respondents were asked to choose from predefined answer options. Lindh et al. [17] grouped open-ended answer options to correspond with the three main packaging functions identified from packaging theory (to protect, to facilitate handling, and to communicate) and according to material considerations. In the free response answers, only $8 \%$ of the consumers explicitly mentioned the need for packaging to protect the food, and only $2 \%$ mentioned shelf life. Most of the consumers focused on the importance of packaging being easy to re-seal and easy to open, and the packaging size. This shows that consumers evaluate the quality of packaging not only in a purchasing situation, but also as they consume and use the contained product.

In a study by Steenis et al. [22], where 3224 cue perceptions on packaging were categorized into 28 content categories, and then further divided into abstract and concrete cue perceptions, "preservable" was ranked as number 11 out of 12 elicited cue perception descriptions per category.

In the study described here, consumer perception of the packaging benefits of an extended shelf life (36\%), and particularly an avoidance of food waste (23\%), appear to be far higher than in studies in which predefined answers have not been offered. Nevertheless, although the study participants do perceive the protective function of food packaging and name it as its most important function in terms of technical, hygienic, and shelf life extending product protection, the link to the simultaneous reduction of food waste appears to be missing. Only about a quarter of the respondents state that one of the most important functions of food packaging is the reduction of food waste, and only $6 \%$ recognize the protective function of packaging at home. In general, only around $50 \%$ recognize the advantages of the original packaging. 


\subsection{Influence of Packaging on Purchase Decision}

Several aspects can influence consumers' selection of food products. These include product characteristics such as taste, quality, origin, brand, and price, and also external characteristics such as labelling and packaging.

Only $19 \%$ of the surveyed consumers state packaging as the reason for their purchase decision. Most of the respondents choose products because of their origin, price, and of course quality and taste. In Austria, regionality of food is of special interest: $83 \%$ of participants ranked this as the most important factor concerning their choice of food.

In a US study, freshness and shelf life achieved only 5th place out of 7 decision-making factors for food purchasing [23]. In the same study focusing on produce packaging, in which "extend the 'best by' date" was ranked as the top convenience feature, the type of packaging material was considered to affect the food product quality $(92.7 \%)$, and containers made from bio-based materials were highly appealing. According to the results generated by Koutsimanis [23], the most important attributes affecting the purchasing decisions of consumers regarding fresh produce such as sweet cherries are price $(25 \%)$, shelf life $(19 \%)$, and container size $(17.2 \%)$.

A review written by Popovic et al. [24] suggests that although extant research in this area is growing, it remains very limited in terms of the theories utilized to explain consumer purchasing behavior. Plumb et al. [19] conclude that attitudes to packaging shift according to the context and consumers' mind-set. Their findings include the fact that in a shopping context, packaging is a low-order priority and plays only a supporting and practical role in product choice (aspects of packaging, such as resealability, can influence choice). They also report that when framed in the wider context of food issues, only a small minority identify packaging as advantageous, which can be compared with the results described here.

In order to become environmentally friendly, the consumer needs to develop an ecological awareness by informing themselves of and understanding the ecological consequences of their behavior, and as a result of their attitude towards ecological aspects and products, modify their behavior towards sustainable consumption [13]. There are several models explaining sustainable consumer behavior [13], but correlations between environmental attitudes and purchase behavior are low [13]. In the present case, this is all the more true because the connection between packaging and food waste is not directly visible, as would be the case, for example, with environmentally friendly packaging.

It is shown in this study, as well as in the investigation carried out by Plumb et al. [19], that as soon as consumers recognize the advantages of packaging, the perception of packaging changes and product selection is very likely to be based on specific packaging. It was found in the WRAP study [19] that when asked to choose between two cheese products, one with reclosable packaging and the other without, one in five $(20 \%)$ of the consumers who chose the resealable pack specifically cited the reclosable function as the main reason for their choice. In the study described here, the indications were even clearer. When participants were asked to choose between cream cheese products, $85 \%$ of those who chose the split pack stated portion size as their reason, while $63 \%$ chose the split pack due to prolonged freshness. When asked to choose between ham products, participants who chose the resealable tray were mainly influenced by resealability $(67 \%)$. For both variants of packaged ham product, the reason given for purchase choice was that the product can be stored unopened for a longer period (than unpackaged ham) $(<40 \%)$. Other reasons such as product protection or "no waiting time" were less important.

According to Koutsimanis [23], there is a lack of general information in the literature about preferences for packaging materials, ratings of packaging convenience features, preferences for container characteristics, and desired produce shelf life, among others. Specifically, Lindh et al. [9] used a sample of Swedish consumers to demonstrate that "easy open", "resealable", "ease of transport", "disposal", and "storage in the home" constitute the primary drivers for purchase. Illustrated by the outcomes of this study and also described by Plumb et al. [19] is the fact that before packaging has an impact on a purchase decision, the consumer must be aware of the benefits of the packaging. This can be seen 
as another challenge for packaging designers. It is essential to find ways to communicate the benefits of packaging features, such as resealability and the size of the packaging unit, in terms of shelf life extension and food waste prevention to the consumer, as they are evidently not obvious to the consumer at first sight.

This is a challenge; in the results discussed here, only about half of the participants claimed to have seen and also followed storage instructions on sensitive goods such as meat and sausages. A clear majority of consumers did not even notice them for fruit and vegetables. Furthermore, only $12 \%$ of respondents who claimed to have recognized storage instructions said that they had also changed their habits accordingly.

\subsection{Adequate Storage of Optimized Packed Products}

In order to be able to determine the potential for food waste reduction through optimized packaging in the household, the habits of the respondents with regard to product storage and the handling of product packaging were examined. It can generally be assumed that incorrectly stored products are disposed of more frequently. On the other hand, correctly used optimized packaging can extend the shelf life of food in the household. The participants were asked about their storage habits and handling of packaging for different products, so that any difference in the handling of the individual product groups could be determined and the further use of the optimized packaging in the household could be ascertained.

Many consumers do not recognize that packaging protects food in their home [19]. While there is recognition that packaging is important to keep the product safe on its way to and in the store, there is less recognition that it plays a role at home. In fact, the prevailing view is the opposite (i.e., that keeping products in the packaging leads them to spoil more quickly). This in turn leads many consumers to adopt unpacking strategies that potentially decrease the longevity of products (i.e., taking products out of their packaging or piercing the packaging to "let it breathe").

When consumers were asked how they store certain products at home after shopping in the study discussed here, there was a clear tendency to store fruit and vegetables outside their original packaging. While more than half of the respondents keep sausages, cheese, and meat in their original packaging; lettuce, cucumbers, and tomatoes tend to be stored without packaging (loose). About a quarter of the respondents take sausages and cheese out of the packaging at home and repack these products for further storage. Fruit and vegetable packaging was often found to have been opened immediately after purchase. For example, almost $30 \%$ of the respondents immediately unpackage strawberries. One of the reasons for doing this was to achieve a better air supply.

Product protection through optimized packaging is therefore lost for a significant proportion of consumers directly after purchase, or at least after the first time the packaging is opened, whereby products are packed in another container or stored loose. The shelflife-prolonging function of the packaging is only able to come into effect if the consumers consciously refrain from repacking the product or storing it loose after the initial opening of the packaging and before consumption.

\subsection{Prolongation of Shelf Life by Optimized Packaging}

Packaging has huge potential to contribute to food waste avoidance and, of course, to contribute to food safety and security [20]. Optimized packaging systems are an important way of preventing premature spoilage of a variety of different food product groups. They are able to protect the food to a very high level and actively extend the shelf life. The increasing use of innovative, active, and intelligent packaging systems for food is therefore to be welcomed.

Using the example of fresh cheese, it was possible to show the difference in shelf life between two types of packaging of the same product within the framework of consumer simulation by means of laymen sensory tests. The comparison of cream cheese in $150 \mathrm{~g}$ pots and portion packaging $(8 \times 15 \mathrm{~g})$ under defined scenarios of everyday usage was in 
favor of the optimized—in this case portioned and thus more heavily packaged—variant. Although consumers nowadays regard food as over-packaged, portion packaging-despite the increased use of packaging resources-offers a sensible way to reduce food waste. The packaging of portions limits the spread of mold and bacteria. This type of packaging is particularly beneficial for foods that are not on the menu every day and are therefore often forgotten in the refrigerator. The online survey showed that $90 \%$ of the respondents would opt for the cup variant and only $10 \%$ would choose the optimally packed product. In this case, therefore, it can clearly be seen that consumers do not perceive the advantages of portion packaging.

Similar results could be shown for other food products, including ham. The advantage of the packaged product in contrast to ham from the delicatessen was evident from the 5 th day onwards. From the 8th day onwards, all test persons would have thrown the ham from the delicatessen away, whereas the packaged variants would have been kept until the 12th day. This results in a longer "associated shelf life" of the packaged forms by about one third. Nevertheless, the online survey showed that $63 \%$ of participants would have chosen the ham from the deli counter packed in deli paper over the packaged variants.

\subsection{Actual Prolonged Use}

One major prerequisite for positive effects of optimized packaging on food waste prevention in households is not only to give produce a theoretically longer shelf life, but also that there must be a real need for consumers to keep the product for longer. For products that are usually consumed within three days, extending the shelf life at the household level to 10 days through optimized packaging makes little sense.

In a UK-based study, $9 \%$ of purchased cheese was estimated to end up as waste [25]. The reason for $77 \%$ of this waste was "not used in time", and about one third of that was due to an expired "best-before date". The disposal of $42 \%$ of the waste was in its original packaging, which had mostly been opened. Therefore, it can be concluded that as a large share is wasted or unused, without citing date labelling as a reason, a probable reason is insufficient protection during storing [26].

For a service to be provided, food packaging must have functions that are aligned with user needs. To illustrate, if a package is easy to empty but the consumer never uses more than half of the contents and then throws the package into the bin unemptied, the service cannot be provided. Likewise, if a package is easy to reseal, but it provides unclear information regarding the food security of the opened package, the consumer might discard any leftovers after the first use. Thus, there is a delicate balance in the design of packaging functions for certain food products that provide a service to different users in different contexts, while at the same time reducing their food waste.

The results from the food diaries reveal that, with the exception of butter, all food products are usually consumed within a few days. Typically, less than 4 days elapse before the consumption of lettuce, peppers, strawberries, sausages, and meat, while other food products remained in the household for no longer than 6 days. In this respect, a future focus on optimizing packaging to extend the shelf life of products in the household should be questioned.

\section{Conclusions}

Evaluation of the online survey and focus groups highlights the fact that the functionality of packaging usually ends after purchase by the consumer. The type of packaging plays a rather subordinate role in the purchase decision, and many customers do not even notice optimized packaging. This is also reflected in the handling of the products immediately after purchase in one's own four walls. Product packaging is often opened prior to the first consumption, and the contained foodstuffs are either repacked in storage containers (primarily made of plastic and glass) or are stored loose.

This study has major managerial implications, as it notifies decision-makers and marketing managers that consumers are only slightly aware of the advantages of packaging 
in the household. Households are not aware of the general direct connection between packaging, freshness, shelf life, and spoilage as food waste. It is also relevant for decisionmakers that consumers rarely or never use optimized packaging at home. Mostly, the shelflife-extending function of food packaging is not perceived as such. Existing storage habits determine how the product is handled, regardless of the specific packaging. Packaging has been and is constantly being improved, not least to protect food in the best possible way and keep it fresh. It is important for those responsible to know that these efforts are not perceived by the consumer. This will enable them to decide in the future whether to invest more in consumer information or to focus optimized packaging more on transport and retail, and less on the consumer. In this context, it also seems relevant that the duration of the product's stay in the household or the average consumption time for many products is far below the expected values, which means that the shelf life extension function is not always relevant.

One of the main theoretical implications is that food is often unpacked or repacked after the packaging is opened for the first time, or even directly after purchase. This is particularly true for fruit and vegetables, which tend to be taken out of the packaging directly after purchase, whereby the benefit of the optimized packaging is lost. Consumers are most likely to use the original packaging for cheese, meat, and sausages, whereas less than $30 \%$ of participants keep tomatoes in the original unopened packaging.

It is indicated that, in general, consumers have a rather negative attitude towards food packaging; food is perceived as "over-packaged". From the consumer's point of view, environmentally friendly packaging is preferred to the functionality of optimized packaging. Although consumers nowadays see food as over-packaged, portion packagingdespite the increased use of packaging resources-offers one of the few sensible ways to reduce food waste for consumers. The packaging of portions limits the spread of mold and bacteria. This type of packaging is especially beneficial for foods that are not on the menu every day and are therefore often forgotten in the refrigerator. Both the results of the consumer simulation investigating the actual shelf life of food products in use, and the surveys on the perception and preference for certain packaging sizes reveal clear advantages for portion packaging. In this case, the higher environmental impact due to the higher quantity of packaging is countered by the potential food waste reduction at the consumer level.

In summary, it can be stated that in contrast to its use in retail and transport, an optimization of packaging to avoid food waste for later use by the consumer only shows an effect in exceptional cases, or can only be achieved through targeted information campaigns.

Author Contributions: The manuscript of this paper, as well as the conceptualization and planning of the methodology of the study, was mainly prepared by G.O., while M.C., S.L., and J.M. were active in implementing the studies. J.M. was active in reviewing, providing comments, and editing the manuscript. All authors have read and agreed to the published version of the manuscript.

Funding: This research was funded by the Austrian Research Promotion Agency (FFG) in the framework of the research project STOP waste-SAVE food (2016-2020) and co-financed by the Austrian producer responsibility organizations (PROs) for packaging.

Institutional Review Board Statement: Not applicable.

Informed Consent Statement: Informed consent was obtained from all subjects involved in the study.

Data Availability Statement: Not applicable.

Conflicts of Interest: The authors declare no conflict of interest. 


\section{References}

1. Tukker, A.; Huppes, G.; Guinée, J.; Heijungs, R.; de Koning, A.; van Oers, L.; Suh, S.; Geerken, T.; Van Holderbeke, M.; Jansen, B.; et al. Environmental Impact of Products. EIPRO 2006. Available online: http:/ / ec.europa.eu/environment/ipp/pdf/eipro_ report.pdf (accessed on 9 April 2021).

2. Gustavsson, J.; Cederberg, C.; Sonesson, U. Global Food Losses and Food Waste: Extent, Causes and Prevention. Study Conducted for the International Congress Save Food! At Interpack 2011, [16-17 May], Düsseldorf, Germany; Food and Agriculture Organization of the United Nations: Rome, Italy, 2011.

3. Stenmarck, Å.; Jensen, C.; Quested, T.; Moates, G. Estimates of European Food Waste Levels; Report of the Project FUSIONS (Contract Number: 311972) Granted by the European Commission (FP7); European Commission: Brussels, Belgium, 2016; ISBN 978-91-88319-01-2.

4. Scherhaufer, S.; Moates, G.; Hartikainen, H.; Waldron, K.; Obersteiner, G. Environmental impacts of food waste in Europe. Waste Manag. 2018, 77, 98-113. [CrossRef] [PubMed]

5. PlasticsEurope. Plastics-The Facts 2018. An Analysis of European Plastics Production, Demand and Waste Data. 2018. Available online: https:/ / www.plasticseurope.org/application/files / 6315/4510/9658/Plastics_the_facts_2018_AF_web.pdf (accessed on 9 April 2021).

6. Coles, R.; McDowell, D.; Kirwan, M.J. Food Packaging Technology; CRC Press: Boca Raton, FL, USA, 2003.

7. Schaefer, D.; Cheung, W.M. Smart Packaging: Opportunities and Challenges. Procedia CIRP 2018, 72, 1022-1027. [CrossRef]

8. Hellström, D.; Saghir, M. Packaging and logistics interactions in retail supply chains. Packag. Technol. Sci. 2006, 20, 197-216. [CrossRef]

9. Lindh, H.; Olsson, A.; Williams, H. Consumer Perceptions of Food Packaging: Contributing to or Counteracting Environmentally Sustainable Development? Packag. Technol. Sci. 2016, 29, 3-23. [CrossRef]

10. Pilz, H.; Aspalter, K.; Hutterer, H.; Schweighofer, J.; Krainz, M. Vermeidung von Lebensmittelabfällen durch Verpackung. Kooperationsprojekt mit Partnern aus den Bereichen Rohstoffherstellung, Verpackungsproduktion, Handel, Verpackungsverwertung und Forschung; denkstatt GmbH: Wien, Austria, 2014.

11. Boesen, S.; Bey, N.; Niero, M. Environmental Sustainability of Liquid Food Packaging: Is There a Gap between Danish Con-sumers' Perception and Learnings from Life Cycle Assessment? J. Clean. Prod. 2019, 210, 1193-1206. [CrossRef]

12. Orzan, G.; Cruceru, A.F.; Bălăceanu, C.T.; Chivu, R.-G. Consumers' Behavior Concerning Sustainable Packaging: An Exploratory Study on Romanian Consumers. Sustainability 2018, 10, 1787. [CrossRef]

13. Jariyasakoolroj, P.; Leelaphiwat, P.; Harnkarnsujarit, N. Advances in research and development of bioplastic for food packaging. J. Sci. Food Agric. 2020, 100, 5032-5045. [CrossRef] [PubMed]

14. Kroeber-Riel, W.; Weinberg, P. Konsumentenverhalten. 8. Aktualisierte und Ergänzte Auflage; Vahlen: Munich, Germany, 2003; Volume XVIII, p. 825 S. ISBN 978-3-8006-2931-2.

15. Zorpas, A.A.; Lasaridi, K. Measuring waste prevention. Waste Manag. 2013, 33, 1047-1056. [CrossRef] [PubMed]

16. Read, M.; Gregory, M.K.; Phillips, P.S. An evaluation of four key methods for monitoring household waste prevention campaigns in the UK. Resour. Conserv. Recycl. 2009, 54, 9-20. [CrossRef]

17. Lindh, H.; Williams, H.; Olsson, A.; Wikström, F. Elucidating the Indirect Contributions of Packaging to Sustainable Development: A Terminology of Packaging Functions and Features. Packag. Technol. Sci. 2016, 29, 225-246. [CrossRef]

18. Brennan, L.; Langley, S.; Verghese, K.; Lockrey, S.; Ryder, M.; Francis, C.; Phan-Le, N.T.; Hill, A. The role of packaging in fighting food waste: A systematised review of consumer perceptions of packaging. J. Clean. Prod. 2021, 281, 125276. [CrossRef]

19. Plumb, A.; Downing, P.; Parry, A. Consumer Attitudes to Food Waste and Food Packaging: A Qualitative and Quantitative Investigation into Consumer Attitudes to, and Behaviour Around, Food Waste and Food Packaging, which Will Inform Action to Help Further Reduce Household Food Waste; WRAP: Barbury, UK, 2013.

20. Wohner, B.; Pauer, E.; Heinrich, V.; Tacker, M. Packaging-Related Food Losses and Waste: An Overview of Drivers and Issues. Sustainability 2019, 11, 264. [CrossRef]

21. Principato, L.; Secondi, L.; Pratesi, C.A. Reducing food waste: An investigation on the behaviour of Italian youths. Br. Food J. 2015, 117, 731-748. [CrossRef]

22. Steenis, N.D.; Van Herpen, E.; Van Der Lans, I.A.; Ligthart, T.N.; Van Trijp, H.C.M. Consumer Response to Packaging Design: The Role of Packaging Materials and Graphics in Sustainability Perceptions and Product Evaluations. J. Clean. Prod. 2017, 162, 286-298. [CrossRef]

23. Koutsimanis, G.; Getter, K.; Behe, B.; Harte, J.; Almenar, E. Influences of Packaging Attributes on Consumer Purchase Deci-sions for Fresh Produce. Appetite 2012, 59, 270-280. [CrossRef] [PubMed]

24. Popovic, I.; Bossink, B.A.G.; Van Der Sijde, P.C. Factors Influencing Consumers' Decision to Purchase Food in Environmentally Friendly Packaging: What Do We Know and Where Do We Go from Here? Sustainability 2019, 11, 7197. [CrossRef]

25. Quested, T.; Murphy, L. Household Food and Drink Waste: A Product Focus; WRAP: Oxon, UK, 2014.

26. Wikström, F.; Verghese, K.; Auras, R.; Olsson, A.; Williams, H.; Wever, R.; Grönman, K.; Pettersen, M.K.; Møller, H.; Soukka, R. Packaging Strategies That Save Food: A Research Agenda for 2030. J. Ind. Ecol. 2018, 14, 1346. [CrossRef] 